\title{
Regional experiences in organic apple production differ
}

Janet Caprile

This section showcases cooperative research efforts between UC personnel and growers in several regions of the state. Findings from such demonstration projects and field research can provide the groundwork for further studies in other fruit-producing areas of California. We publish these articles in response to the groundswell of grower interest in more sustainable farming practices. $-E d$.

The following three articles present separate comparisons of organic versus conventional apple-production systems. Each study examines a set of orchards in one of the three major apple-producing regions of California - the Sonoma area, the Santa Cruz area and the northern San Joaquin Valley.

The apple industry in each of these regions has a unique character due to differences in climate, pests, production systems, varieties, economics and marketing options. It is not surprising, therefore, to find that each of these studies presents a somewhat different picture regarding the "success" of organic production in these different regions. Additionally, it should be kept in mind that these comparisons are preliminary because the organic production systems and markets are still in flux.

Common to all regions was the ability to maintain fertility in both the organic and conventional systems. Organic fertility practices varied from site to site, based on the needs of the particular orchard and the availability of suitable organic materials. Practices included the addition of leguminous cover crops, composts, mined minerals and/or foliar kelp and fish sprays. Although there were occasional differences between nutrient levels in the organic and conventional systems, the levels were adequate in both systems at all locations and did not limit yields. We clearly have the tools to address a wide range of fertility needs in organic apple orchards.

The picture is less clear with regard to pest management practices. Our ability to adequately control major yield-limiting pests with organic techniques varied with the pest pressure in each region and each site.

Codling moth was a major yieldlimiting pest in the Sonoma and Contra Costa County comparison sites. Organic sprays have not been successful in controlling codling moth in areas with an established population and high codling moth pressure. Pheromone confusion techniques worked well in orchards with low codling moth pressure, but not in those with higher pressure. Combining pheromone confusion techniques with supplemental controls such as organic sprays or wasp releases has proved promising in some of the higher-pressure situations. However, these combination approaches need further study and refinement to determine their limits and effectiveness.

Apple scab seriously limited yields in the high-rainfall organic site (Sonoma County). Lime sulfur provided fairly good protection against this disease when rain occurred before or during bloom. However, when rainfall extended past bloom, as it frequently did in Sonoma County, the standard organic option (sulfur) was not as effective as conventional alternatives in protecting against this disease. In addition, sulfur contributed to increased russeting on Red Delicious apples. A number of other organic scab options are currently under review in the North Coast.

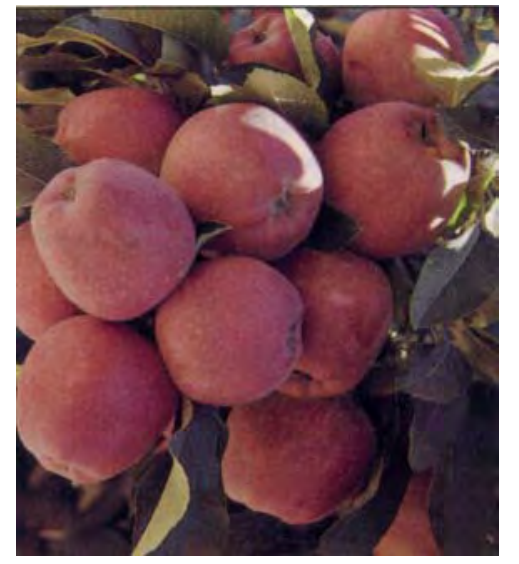

Rosy apple aphid contributed to major yield losses in the Central Valley organic site (Contra Costa County) in 2 out of 4 years. The beneficial insects that control this pest in the northern San Joaquin Valley (ladybird beetles, lacewings, syrphid flies) require higher temperatures for development than the aphid. In years with prolonged cool springs, the beneficials have not kept pace with the aphids, and severe damage has resulted. Organic sprays (soap or pyrellin) have had little effect in reducing populations. Releases of predatory midges (Aphidoletes aphidomyza) and remedial pruning for the control of this pest are currently under examination.

The economic viability of the various organic systems closely follows the level of pest management success in the orchard. In most years the organic systems had somewhat higher expenses, due to increased labor and material costs. The price premium received for the organic product usually offset the increased production expense. The factor that determined whether the return was greater or less than the comparable conventional system was the degree of yield reduction (if any) caused by pest problems that could not be controlled organically. In the Santa Cruz comparison, where environmental conditions resulted in low pest incidence, the organic system was more profitable than the conventional counterpart. In the North Coast and northern San Joaquin Valley organic sites, there were still yield-limiting pest problems in most years that needed effective solutions before organic returns could compare with conventional.

\section{J. Caprile is Farm Advisor, Contra Costa County.}

